УДК 581.84. 577:543.53

\title{
ЭЛЕМЕНТНЫЙ СОСТАВ ТРАВЫ КОРОСТАВНИКА ПОЛЕВОГО КNАUTIА ARVENSIS (L.) COULT.
}

\author{
() И.Л. Дроздова", Н.Н. Денисова
}

Курский государственный медицинский университет, ул. К. Маркса, 3, Курск, 305041 (Россия), e-mail: irina-drozdova@yandex.ru

В статье приведены результаты изучения элементного состава травы короставника полевого (Knautia arvensis (L.) Coult.). Установлено, что трава короставника полевого содержит 22 макро-, микро- и ультрамикроэлемента, из которых десять являются эссенциальными и пять - условно эссенциальными. Элементный состав травы короставника полевого изучен впервые.

Ключевые слова: короставник полевой, элементный состав.

\section{Введение}

Известно, что 31 соединение является незаменимыми компонентами пищи человека, из них: 12 витаминов, восемь аминокислот, 11 минеральных элементов [1].

Основным биологическим аккумулятором минеральных веществ являются растения. Они поглощают минеральные вещества из почвы и других субстратов корневой системой и с помощью транспирационного тока воды обеспечивают ими ткани и органы (семена, плоды, листья, стебли) растительного организма. Минеральные вещества, попадая в организм человека, выполняют функцию регуляторов основных процессов жизнедеятельности [2], стимулируют и нормализуют обмен веществ [9]. Было установлено, что многие из макро- и микроэлементов способны предупредить развитие некоторых болезней. Дефицит макро- и микроэлементов способен вызвать развитие патологического процесса в организме человека. Так, катионы a участвуют в поддержании кислотно-щелочного равновесия и осмотического давления внеклеточных жидкостей. Ионы Са активируют действие многих ферментов, способствуют свертыванию крови, регулируют проницаемость клеточных мембран. Ионы Fе входят в лекарственные препараты для лечения анемии. Mg снимает усталость, нервное напряжение, способствует лучшему усвоению Са. Он усиливает иммунитет, сопротивляемость и устойчивость нормальных клеток к канцерогенным факторам, способствует предупреждению атеросклероза и инфаркта. Микроэлементы Co, Zn, Мп входят в состав многих металлоферментов, участвуют в процессах кроветворения. Со является составной частью витамина $\mathrm{B}_{12 .}$ Мп активирует работу многих ферментов растительного организма, участвует в биосинтезе биологически активных соединений. [2]. Роль микроэлементов объясняется тем, что они входят в состав дыхательных пигментов, витаминов, гормонов, ферментов и коферментов, участвующих в регуляции жизненных процессов [17].

Выявлено, что биологической ценностью обладают лишь доступные биогенные элементы, содер-

Дроздова Ирина Леонидовна - декан фармацевтического и биотехнологического факультетов, профессор кафедры фармакогнозии и ботаники, доктор фармацевтических наук, тел.: (4712) 58-81-35, e-mail: irina-drozdova@ yandex.ru Денисова Наталья Николаевна - аспирант кафедры фармакогнозии и ботаники жащиеся в пищевых продуктах, лекарственном растительном сырье и продуктах их переработки в виде солей органических кислот и других растворимых химических соединений, чаще всего комплексных. К биогенным элементам отнесены: K, $\mathrm{Na}, \mathrm{Mg}, \mathrm{Ca}, \mathrm{P}, \mathrm{N}$, $\mathrm{O}, \mathrm{C}, \mathrm{Cl}, \mathrm{Fe}, \mathrm{Mn}, \mathrm{Zn}, \mathrm{Co}, \mathrm{V}, \mathrm{Cr}, \mathrm{Ni}, \mathrm{Cu}, \mathrm{Mo}, \mathrm{I}, \mathrm{Se}, \mathrm{Si}, \mathrm{F}$, $\mathrm{Br}$, As и, возможно, Sn [7].

\footnotetext{
* Автор, с которым следует вести переписку.
} 
Из 92 встречающихся в природе элементов 81 обнаружен в организме человека, при этом 15 из них (Ca, P, K, Cl, Na, Zn, Mn, Mo, I, Se, S, Mg, Fe, Cu, Co) признаны эссенциальными, т.е. жизненно необходимыми (биогенными), а десять (F, Si, Ti, V, Cr, Ni, As, Br, Sr, Cd) относят к вероятно (условно) необходимым (условно эссенциальным элементам) [12,13].

По классификации, основанной на количественном признаке, все минеральные элементы делятся на три группы в соответствии с их содержанием в организме: макроэлементы (Ca, P, K, $\mathrm{Na}, \mathrm{S}, \mathrm{Cl}, \mathrm{Mg})$, микроэлементы (Fe, Zn, F, Sr, Mo, Cu, Br, Si, Cs, J, Mn, Al, Pb, Cd, B, Rb), ультрамикроэлементы ( $\mathrm{Se}, \mathrm{Co}, \mathrm{V}, \mathrm{Cr}$, As, Ni, Li, Ba, Ti, Ag, Sn, Be, Ga, Ge, Hg, Sc, Zr, Bi, Sb, U, Th, Rh) [13].

Для нормального функционирования организма человека макро- и микроэлементы требуются лишь в оптимальных количествах, отсутствие или недостаток минеральных веществ в питании, так же как и их избыток, вызывают резкое нарушение обмена веществ и как следствие - заболевание и даже гибель [17]. В формировании целого ряда важнейших адаптивных механизмов, включая поддержание функционирования всех жизненно-важных систем - сердечно-сосудистой, дыхательной, пищеварительной, иммунной, эндокринной и др., микроэлементам принадлежит немаловажная роль. В связи с этим, полноценное содержание эссенциальных элементов составляют один из важнейших компонентов здоровья человека [15].

Изменения состава и содержания макро- и микроэлементов в организме человека вызывают немедленный отклик отдельных его систем. При обнаружении признаков дисэлементозов на ранней стадии можно провести коррекцию элементного баланса в организме путем медикаментозной терапии или введением в рацион питания различных микронутриентов [17].

Исследование элементного состава сырьевой части перспективных для внедрения в медицинскую практику лекарственных растений является актуальным, так как известно, что макро- и микроэлементы, входящие в состав растения, оказывают немаловажное влияние на проявление биологической активности суммарных извлечений, получаемых из них [8].

До настоящего времени лекарственные растения не рассматривались в качестве источника легкоусвояемой формы микроэлементов в комплексе с другими биологически активными веществами для лечения и профилактики ряда заболеваний. Поэтому минеральный состав многих лекарственных растений до сих пор не изучен.

В этом плане значительный интерес представляют растения рода Короставник семейства Ворсянковые, которые нашли широкое применение в народной медицине.

Род Короставник - Knautia L. - относится к семейству Ворсянковые (Dipsacaceae) и включает около 50 видов, наиболее распространенных в Европе. В СНГ встречаются шесть видов, преимушественно на Кавказе. Во флоре России произрастают два вида, из которых широко распространен короставник полевой Knautia arvensis (L.) Coult. [3, 10, 14, 16].

Короставник полевой - многолетнее травянистое растение, высотой 40-80 см, с многоглавым корневищем и прямостоячим бороздчатым стеблем. Листья серовато-зеленые, супротивные, лировидные или перисто-раздельные, иногда цельные, обычно жестковолосистые, нижние - с черешками, верхние - сидячие, длиной 4-20 см. Цветки розовато-лиловые, мелкие, 7-10 мм длиной, собраны в соцветия - головки. Плоды - продолговато-яйцевидные семянки, густоопушенные, зеленовато-желтого цвета [4, 10, 16]. Цветет с июня до поздней осени, плоды созревают в июле - октябре $[4,16]$.

Короставник полевой - евроазиатское растение, широко распространенное почти по всей Европе, в Западной Сибири, Казахстане. В России произрастает в европейской части (кроме северных районов), на Северном Кавказе, на Юге Западной Сибири, как заносное - на Сахалине. В Средней России растет во всех областях. Общий ареал распространения: лесная зона, лесной и субальпийский пояс Европы, Западной Сибири и Предкавказья. Во всех областях Центральной России данный вид широко встречается по лугам, по разреженным лесам и опушкам, среди кустарников, по паровым полям, на пастбищах $[4,10,11,16]$.

Цель нашей работы заключалась в исследовании элементного состава травы короставника полевого (Knautia arvensis (L.) Coult.), семейства Ворсянковые (Dipsacaceae), широко распространенного во флоре областей Центральной России.

\section{Экспериментальная часть}

Объектом исследования служила воздушно-сухая измельченная трава короставника полевого. Сырье заготавливалось в 2010-2011 гг. в Курской области в период массового цветения растений. 
Методы исследования. Качественный состав и количественное содержание минеральных элементов определяли методом эмиссионного спектрального анализа. Образцы сырья измельчали, подвергали озолению в муфельной печи при температуре $450-500{ }^{\circ} \mathrm{C}$ при доступе воздуха в течение 2 ч. Полученную золу после охлаждения в эксикаторе взвешивали на аналитических весах и анализировали на спектрографе ДФС-8-1 (Россия). Фотометрирование спектрограмм проводили с помощью атласа спектральных линий и спектров-стандартов с погрешностью не более $2 \%$ в пересчете на золу $[5,6]$.

\section{Обсуждение результатов}

Результаты определения элементного состава травы короставника полевого представлены в таблицах 1,2 . Как следует из данных таблицы 1 , трава короставника полевого богата биологически активными макро-, микро- и ультрамикроэлементами, из которых десять являются эссенциальными и пять - условно эссенциальными. Использованная методика позволила определить количественное содержание 22 элементов, содержание которых представлено в виде ряда в зависимости от уменьшения их количественного содержания (табл. 2). Установлено, что кроме натрия, кальция, калия, магния, кремния, фосфора, которые в больших количествах накапливают почти все растения, трава короставника полевого содержит значительные количества алюминия, железа, марганца, цинка, бора, бария, титана, меди, а также содержит все незаменимые микро-, макро- и ультрамикроэлементы.

Полученные данные позволяют отметить, что трава короставника полевого содержит значительные количества многих важнейших минеральных элементов (в первую очередь эссенциальных). В комплексе с другими БАВ (полисахаридами, фенольными соединениями, органическими кислотами) это подчеркивает терапевтическую значимость и дает возможность создания новых ценных препаратов комбинированного действия на основе указанного вида лекарственного растительного сырья.

Таблица 1. Содержание минеральных элементов в траве короставника полевого, \%

\begin{tabular}{|c|c|c|c|}
\hline Химический элемент & $\begin{array}{c}\text { Содержание элементов в } \\
\text { образце }\end{array}$ & Химический элемент & $\begin{array}{c}\text { Содержание элементов в } \\
\text { образце }\end{array}$ \\
\hline \multicolumn{2}{|c|}{ Макроэлементы } & Бор & 0,03 \\
\hline Калий* & 20 & Алюминий & 0,6 \\
\hline Натрий* & 1 & \multicolumn{2}{|c|}{ Ультрамикроэлементь } \\
\hline Кальций* & 5 & Никель** & 0,002 \\
\hline Магний* & 8 & Титан** & 0,02 \\
\hline Фосфор* & 6 & Ванадий** & 0,0003 \\
\hline \multicolumn{2}{|c|}{ Микроэлементы } & Хром** & 0,001 \\
\hline Медь* & 0,01 & Барий & 0,03 \\
\hline Цинк* & 0,05 & Цирконий & 0,002 \\
\hline Молибден* & 0,0003 & Серебро & 0,00001 \\
\hline Марганец* & 0,15 & Галлий & 0,0003 \\
\hline Железо* & 0,3 & Бериллий & 0,0005 \\
\hline
\end{tabular}

Примечания: * эссенциальные элементы; ** условно-эссенциальные элементы.

Таблица 2. Результаты определения количественного содержания химических элементов в траве короставника полевого

\begin{tabular}{c|c}
\hline $\begin{array}{c}\text { Количество обнаружен- } \\
\text { ных элементов }\end{array}$ & Ряд химических элементов в порядке убывания их содержания в лекарственном расти- \\
тельном сырье
\end{tabular}

\section{Bblводbl}

Анализ минерального состава надземной части короставника полевого показал наличие 22 минеральных элементов. Преобладающими являются К, Mg, P, Ca, Si, Na, Al, Fe, Mn, Zn, B, Ba, Ti, Cu. Достаточно богатый минеральный состав травы короставника полевого позволяет рекомендовать его в качестве сырья, богатого макро-, микро- и ультрамикроэлементами.

Значительные количества многих важнейших элементов, обнаруженные при анализе данного лекарственного растительного сырья, подчеркивают их терапевтическую значимость и позволяют расширить возможности медицинского использования. 


\section{Список литературы}

1. Петрушевский В.В., Гладких В.Г., Винокурова Е.В. БАВ пищевых продуктов : справочник. Киев, 1992. 192 с.

2. Белоусов М.В., Цыбукова Т.Н., Березовская Т.П., Тихонова О.К., Басова Е.В., Зейле Л.А., Юсубов М.С. Элементный состав багульника болотного // Химия растительного сырья. 2002. №4. С. 35-38.

3. Дикорастущие полезные растения России / Отв. ред. А.Л. Буданцев, Е.Е. Лесиовская. СПб., 2001. 663 с.

4. Губанов И.А., Киселёва К.В., Новиков В.С., Тихомиров В.Н. Иллюстрированный определитель растений Средней России. Т. 3. Покрытосеменные (двудольные: раздельнолепестные). М., 2004. 520 с.

5. Муравьева Д.А., Попова О.И., Мартынова Н.Н., Пшукова И.В., Яковлева С.Г. Исследование микроэлементного состава объектов растительного происхождения // Достижения современной фармацевтической науки и образования - практическому здравоохранению: материалы юбилейной науч.-практич. конф., посвящ. 60летию Пермской гос. фармац. академии. Пермь, 1997. С. 224.

6. Калинин С.К., Явнель А.А., Алексеева А.И., Неймарк А.Э. Атлас спектральных линий для кварцевого спектрографа. М., 1959. 53 с.

7. Крисс Е.Е., Волченскова И.И., Григорьева А.С., Коханович Н.Ф. Координационные соединения металлов в медицине. Киев, 1986. 216 с.

8. Кукушкин Ю.Н. Химические элементы в организме человека // Соросовский образовательный журнал. 1998. №5. C. 54-58.

9. Лукманова К.А., Рябчук В.А., Салихова Н.Х. Аминокислотный и минеральный состав фитопрепарата люцерон // Фармация. 2000. №2. С. 25-27.

10. Маевский П.Ф. Флора средней полосы европейской части России. М., 2006. 600 с.

11. Полуянов А.В., Прудников Н.А. Сосудистые растения Курской области: учебное пособие. Курск, 2005. 80 с.

12. Скальный А.В., Рудаков И.А. Биоэлементы в медицине. М., 2004. 272 с.

13. Скальный А.В. Химические элементы в физиологии и экологии человека. М., 2004. 216 с.

14. Скворцов В.Э. Иллюстрированное руководство для ботанических практик и экскурсий в Средней России. М., 2004. $506 \mathrm{c}$.

15. Уланова Т.С., Стенно Е.В., Вейхман Г.А., Баканина М.А. Методические особенности пробоподготовки при определении содержания металлов в желчи // Курский научно-практический вестник «Человек и его здоровье». 2011. №2. С. 138-141.

16. К Киселева К.В., Майоров С.Р., Новиков В.С. Флора средней полосы России: Атлас-определитель. М., 2010.544 с.

17. Ханина М.Г., Ханина М.А., Родин А.П. Элементный состав Agrimonia pilosa Ledeb. // Химия растительного сырья. 2010. №2. С. 99-104. 
Drozdova I.L. , Denisova N.N. ELEMENTAL COMPOSITION OF THE HERB OF KNAUTIA ARVENSIS (L.) COULT.

Kursk State Medical University, st. Marx, 3, Kursk, 305041 (Russia), e-mail: irina-drozdova@yandex.ru

In this study, the elemental composition of the herb of Knautia arvensis (L.) Coult. Found that herb of Knautia arvensis contains 22 macro-, micro- and ultramicroelements, 10 of which are essential and 5 - conditional essentiality. Elemental composition of the herb of Knautia arvensis (L.) Coult.. is studied for the first time.

Keywords: Knautia arvensis (L.) Coult., elemental composition.

\section{References}

1. Petrushevskii V.V., Gladkikh V.G., Vinokurova E.V. BAV pishchevykh produktov: Spravochnik. [BAS food Handbook.]. Kiev, 1992, 192 p. (in Russ.).

2. Belousov M.V., Tsybukova T.N., Berezovskaia T.P., Tikhonova O.K., Basova E.V., Zeile L.A., Iusubov M.S. Khimiia rastitel'nogo syria, 2002, no. 4, pp. 35-38. (in Russ.).

3. Dikorastushchie poleznye rasteniia Rossii. Ed. A.L. Budantsev, E.E. Lesiovskaia. [Wild useful plants of Russia]. St. Petersburg, 2001, 663 p. (in Russ.).

4. Gubanov I.A., Kiseleva K.V., Novikov V.S., Tikhomirov V.N. Illiustrirovannyi opredelitel' rastenii Srednei Rossii. Tom 3. Pokrytosemennye (dvudol'nye: razdel'nolepestnye). [Illustrated Manual of the Middle Russia Plants. Vol. 3. Angiosperms (dicotyledons: razdelnolepestnye)]. Moscow, 2004, 520 p. (in Russ.).

5. Murav'eva D.A., Popova O.I., Martynova N.N., Pshukova I.V., Iakovleva S.G. Dostizheniia sovremennoi farmatsevticheskoi nauki i obrazovaniia - prakticheskomu zdravookhraneniiu: materialy iubileinoi nauch.-praktich. konf., posviashch. 60-letiiu Permskoi gos. farmats. akademii. [The achievements of modern pharmaceutical science and education - practical health care: Proceedings of scientific conference]. Perm, 1997, p. 224. (in Russ.).

6. Kalinin S.K., Iavnel' A.A., Alekseeva A.I., Neimark A.E. Atlas spektral'nykh linii dlia kvartsevogo spektrografa. [Atlas of spectral lines for quartz spectrograph.]. Moscow, 1959, 53 p. (in Russ.).

7. Kriss E.E., Volchenskova I.I., Grigor'eva A.S., Kokhanovich N.F. Koordinatsionnye soedineniia metallov $v$ meditsine. [Metal coordination compounds in medicine]. Kiev, 1986, 216 p. (in Russ.).

8. Kukushkin Iu.N. Sorosovskii obrazovatel'nyi zhurnal, 1998, no. 5, pp. 54-58. (in Russ.).

9. ukmanova K.A., Riabchuk V.A., Salikhova N.Kh. Farmatsiia, 2000, no. 2, pp. 25-27. (in Russ.).

10. Maevskii P.F. Flora srednei polosy Evropeiskoi chasti Rossii. [Flora of the middle belt of the European part of Russia]. Moscow, 2006, 600 p. (in Russ.).

11. Poluianov A.V., Prudnikov N.A. Sosudistye rasteniia Kurskoi oblasti: uchebnoe posobie. [Vascular plants of the Kursk region]. Kursk, 2005, 80 p. (in Russ.).

12. Skal'nyi A.V., Rudakov I.A. Bioelementy v meditsine. [Bioelements in medicine.]. Moscow, 2004, 272 p. (in Russ.).

13. Skal'nyi A.V. Khimicheskie elementy v fiziologii i ekologii cheloveka. [Chemical elements in human physiology and ecology]. Moscow, 2004, 216 p. (in Russ.).

14. Skvortsov V.E. Illiustrirovannoe rukovodstvo dlia botanicheskikh praktik i ekskursii v Srednei Rossii. [Illustrated Guide to practices and botanical excursions in Central Russia.]. Moscow, 2004, 506 p. (in Russ.).

15. Ulanova T.S., Stenno E.V., Veikhman G.A., Bakanina M.A. Kurskii nauchno-prakticheskii vestnik «Chelovek $i$ ego zdorov'e», 2011, no. 2, pp. 138-141. (in Russ.).

16. Kiseleva K.V., Maiorov S.R., Novikov V.S. Flora srednei polosy Rossii: Atlas-opredelitel'. [Flora of central Russia: Atlas determinant]. Moscow, 2010, 544 p. (in Russ.).

17. Khanina M.G., Khanina M.A., Rodin A.P. Khimiia rastitel'nogo syr'ia, 2010, no. 2, pp. 99-104. (in Russ.).

Received September 29, 2012

Revised October 25, 2012

\footnotetext{
* Corresponding author.
} 
